\title{
Notification and Communication Technology: An Observational Study of Call Light Systems in Nursing Homes
}

Haneen Ali ( $\sim$ hba0007@auburn.edu )

Auburn University https://orcid.org/0000-0003-3303-8200

Huiyang Li

Binghamton University

Research article

Keywords: ,

Posted Date: August 23rd, 2019

DOl: https://doi.org/10.21203/rs.2.13461/v1

License: (c) (i) This work is licensed under a Creative Commons Attribution 4.0 International License.

Read Full License 


\section{Abstract}

Background and Objectives: The call light system is one of the major communication technologies that links the nursing home staff to the needs of the residents. By providing residents with the ability to request assistance, the system becomes an indispensable resource for patient-focused healthcare. However, there is little known about how the call light systems are being used in nursing homes and how the system contributes to the safety and the quality of care for seniors. Therefore, the aims of this study are to understand the nursing home staff experience while using the call light systems and to uncover the usability issues associated with the implemented systems. Method: A mix of 150 hours of hypotheticdeductive (unstructured) and 90 hours of standard-procedure (structured) observational study were conducted in four different nursing homes. The data collected includes insights into the nursing homes work system and the process of locating and responding to call lights. Results: The data shows that the highest alarm rate is before and after meal times. The nursing staff exceeded the allotted time set by administration $50 \%$ of the time. Additionally, the staff canceled $10 \%$ of the call lights and did not immediately assist residents due to high workloads. Further, the staff forgot to come back to assist residents over $3 \%$ of the time. Usability issues such as broken parts, lack of feedback, lack of prioritization, and low/no discriminability are contributing to the long response time. More than $8 \%$ of the time, residents notified the staff about call lights after they waited for a long time, as these residents were left unattended. Conclusion: Nursing homes that are still using old call light systems risk the continuation of usability issues that can affect performance of the staff and contribute to a decline in staff and resident outcomes. While the healthcare industry has been at the forefront of technological advancements and implementation, it is important to recognize the influence of technology in the quality of service delivery for the elderly population in nursing homes and to the nursing homes staff working conditions.

\section{Background}

Long-term care in nursing homes provide a wide range of services for elderly people, especially for those who have cognitive and/or physical problems. The number of residents at such facilities is expected to increase from 15 million in 2000 to 27 million in 2050 in the United States (CDC, 2010). As a result, nursing homes will be an even more essential function in providing long-term geriatric services (5). However, recent scholarship suggests a growing concern regarding the overall safety and quality of care in nursing homes (6). Nursing homes residents usually have cognitive deficits and complex health conditions, and they often take more than one medication, which can increase the risk of medication errors (1). According to the Department of Health and Human Services, one in three residents suffer from harm caused by a medication error, by an infection, or by miscellaneous circumstances related to their treatment.

These issues are widespread in nursing homes due to the lack of appropriate technologies $(3,7)$. Furthermore, most of the attempts to improve healthcare in nursing homes are solely focused on aspects such as improving medical, functional, physical, cognitive, and physiological care, in addition to providing 
more training for the staff (8), but not on the technological aspects. Among the technologies utilized in nursing homes is the call light system, which plays a key role in communication. The call light system is critical for the interaction between the nursing home staff and their residents. Research conducted in other healthcare settings have reported that nurse call systems not only significantly influence overall resident satisfaction in the delivery of their healthcare by creating a communication link between resident and nursing home staff $(9-11)$. Nurse call lights also help to ensure the safety of patients (12). It was also described by Meade et al. (2006) as a 'lifeline' for patients since it is linked with patients' needs and alerts the staff to the situations in which patients may ask for help (12). Nurse call light systems in nursing homes are associated with many ergonomic concerns and usability issues $(3,7)$. Malfunctions of the nurse call light can cause negative medical outcomes, as the literature identifies other healthcare settings whereby a relationship exists between the time it takes to respond to a call light system and unintended consequences such as falls $(13,14)$. CNAs contribute to more than $80 \%$ of direct care to residents. However, they must also respond to different types of alarms such as bed exit, chair exit, and clip alarms (15), as they are ultimately responsible in cases of adverse events such as falls (7). However, their perceptions are rarely considered by administration in the development and selection of new technology $(16,17)$.

The study acknowledges the role of communication technology as a potential solution for challenges in nursing homes, but it is also recognizing the importance of considering its influence on nursing practices (18-20). This paper therefore provides a methodological approach to the study of usability regarding the call light system in nursing homes. The study focuses on the usability issues and challenges facing the staff while interacting and using the system in order to understand the barriers to productive, efficient, and safe use of these systems. The insights of the study inform nursing home management on ways to improve the safety and quality of care for nursing homes residents. The theoretical and methodological framework for usability evaluation is detailed in section 2 .

\section{Methodological approach}

The research presented in this paper employs a cognitive engineering approach to the study of interaction surrounding resident-initiated call lights processes. Cognitive engineering is concerned with the analysis, design, and evaluation of complex systems of people and technology (21). The paper presented iterative observations of continuous interaction with the call light technology, beginning with the staff goal (responding to call lights in less than 5 minutes), leading to an action (being notified, locating, and addressing notifications), and resulting in a change of the system (canceling the alarm after assisting the resident). The research was conducted based on a two-pronged methodological approach to the study of human-computer interaction, qualitative research (specifically ethnography), participant observation, and interaction analysis. In stage one, a hypothetic-deductive approach was used with unstructured observations to identify and assess the process of using the call light system. These observations took place in 4 different nursing homes to uncover the challenges and usability issues associated with the different call light systems in use and to understand the barriers to productive use. 
In stage two, a detailed Task Analysis was used to understand and learn about the process, structure, flow, and attributes of tasks and was conducted in one of the nursing homes. The goals of this second stage is to understand the frequency, sequence, and complexity of call lights, and to generate detailed and precise information on the performance of the staff, and the process of being notified and responding to call lights. This stage was conducted by defining specific tasks, subtasks, and actions to be taken and by using the structured systematic observation approach to collect the needed data.

\section{Methods}

Around 15 hours of semi-structured interviews and more than 150 hours of unstructured observations were conducted by both researchers in four different nursing homes located in Upstate New York. The goal for this case selection is to understand evaluate the different call light systems being used in nursing home. Further the research design seems to determine s how these systems affect other elements in the nursing homework systems (person, tasks, tools and technology, organization, and physical environment), process, and outcomes (22). The semi-structured interviews were conducted with 3 nursing home administrators, 2-unit managers, 2 RNs, 8 CNAs, 4 LPNs, a program coordinator for elder service and 1 nursing faculty with extensive experience of working in and with nursing homes. Interview topics included the following: different roles of the staff, relationships between the staff, teamwork, shifts, technology used in nursing homes and their effectiveness, limitations, and challenges the staff experience when using them. The study expects that how the staff are notified about call lights will not only affect their overall respond time, but also resident satisfaction. Further the study will identify what is the expected time to respond to a call light, the affect or other alarms in the facility and, how staff responds to alarm. Because nursing staff often consider call light notifications as interruptions, adverse events in the facility, how the staff is being notified about adverse events, delays in responding, the reasons for the delay, rounds, and how often staff do rounds $(11,23)$.

A hypothetic-deductive approach was used with the unstructured observation stage. A nonparticipant technique was employed where the observer watched from a distance for this stage of the study $(24,25)$. Observations were conducted in all units of the four nursing homes. The aim of the observation was to collect contextual information, about the daily routines for nursing staff, the overall nursing home environment, and the staff required tasks to perform. Further, the study seeks to gather information about call light technology and other technologies that are implemented in nursing home settings, and to conduct an analysis of ergonomic challenges these implementations faced.

The second stage was conducted in one of the nursing homes to conduct the task analysis. For 90 hours the structured systematic observation approach was employed to collect data related to the process of using the call light system; to record and observe the process of locating and responding to call lights (24, 25).

A standard procedure was used to observe how the staff responded to call lights, and the observers would stand near the nurses' station where they could see the system displays. The observers would take 
notes and use a stopwatch to record the time for each event, as well as observe any action the staff took after a call light alarm was triggered. The study observed: 1) The actual nurse response time for each call bell (the time from the initiation of the call until the time of entering the room); 2) How the nurse located the resident-using the nurses' station display, using the light above the resident's door, or by the resident's verbalizations; 3 ) Whether the CNA actually assisted the resident within the allotted response time. Further, if the nurse assisted the resident at a later time, the study observed how long the resident had to wait; and 4) Whether the CNA canceled the nurse call light at the time of response or forgot to cancel I, causing another CNA (or the same CNA) to respond the same alarm. 201 call light interactions were observed in around three months. The data was collected in both units: short-term care unit (south unit) and long-term care unit (north unit). The data was also collected during different time intervals, including before and after breakfast, before and after lunch, and before dinner. 97 interactions were collected in the south unit and 104 in the north unit. Next, and ANOVA analysis was conducted in order to test whether time and unit type have a significant effect on the call light response time. Both stages were conducted after receiving an oral consent of the staff working at time of data collection. The study was approved by the nursing homes and the university's Institutional Review Boards (IRB).

\section{Settings and Participants}

The observations took place in four skilled nursing homes located in the southern tier of upstate New York. All included regular long-term care units and memory units (serving residents with Alzheimer's and dementia or other patients deemed in need of the special care provided in such units). The number of beds in the facilities ranged from 150 to 381 . Two of the facilities were private care units, one was public (by county) and last facility was run by a nonprofit organization. One hundred and fifty hours of observations were conducted during the three different shifts (morning: typically, 7 a.m. -3 p.m.; afternoon 3-11 p.m.; and night 11 p.m. -7 a.m.). The participants in this study were nursing home staff and residents. CNAs and LPNs working in the different units of the nursing homes were all participants. Residents of nursing homes were also observed in order to study how they influence interactions with different technologies. The task analysis stage was conducted in one public 300-bed nursing home. This nursing home was chosen for this stage because there were many complaints from residents and residents' families about long response time and because of accessibility to the research team.

All relevant aspects of observations were categorized into groups and subgroups using the Systems Engineering Initiative for Patient Safety (SEIPS) model of work system and patient safety as a guide (22). Observations about behavior, linguistic aspects (e.g., speech), extra-linguistic aspects (e.g., sounds/ loudness), and staff and residents' comments were all coded and categorized using the SEIPS model. Two of the researchers categorized the interviews and observations took notes individually, and then multiple focus sessions were conducted to discuss any disagreements on the placement of notes into the main categories.

\section{Results}




\section{Work System}

\section{Staff}

The primary drivers of care, those who care for residents daily, are essential people at a nursing care facility: (1) Registered nurses (RNs). RNs are usually the unit managers and/or supervisor. They graduate from a state accredited nursing program and have been licensed by the state Board of Nursing. They were the units' managers and the ones responsible for the residents' care plans, and the ones that do the assessment in case of fall or any other type of injury. They also were the ones to start and manage IVs and administer any medication by vein. (2) Licensed practical nurses (LPNs), were originally educated and trained to work as bedside nurses in hospitals and are working now in nursing homes, rehabilitation centers, physicians' offices, schools, and clinics. Becoming a licensed practical/vocational nurse requires the completion of a formal training program plus supervised clinical instruction. They all have high school diplomas or its equivalent and have graduated from a program with a license granted by the state Board of Nursing. Their main task is to administer medication, take vital signs, but they are also required to respond to the various alarms in the unit. LPNs work under the close supervision of registered nurses. (3) Certified nurse assistants (CNAs). They all completed a training program at a state-approved facility. They provide most of the direct care and assist residents with their daily activities such as toileting, shower, change clothes, transportation, mealtime, etc.

\section{Organizational Characteristics}

Organizational policies and standards are also important to keep residents safe. According to the nursing homes administrators, all the staff working on the unit are required to respond to every alarm, such as bed and chair exit alarms, and must respond to the call lights within 5 minutes. It was observed that LPNs often ignore call light notifications, in many cases walking past residents in need. It was also observed that it takes more than 5 minutes to respond to a call nurse light; in some cases, these responses can take up to 20 minutes. In many cases, the staff enter the resident's room to ask about their needs and ask them to wait and forget to come back, in which case the residents must use the call light again (see the process section of the results). Many complaints were observed regarding the long response time, and in one of the nursing homes, the administration was studying the option of upgrading the call light system to a new one where they can monitor the response times of the staff to show the residents' families that the response time is within the acceptable range in a way to try to reduce the number of complaints.

Communication across the staff working in the same unit is important for the safety of residents. However, there is no system for the staff to communicate in the same unit or between the staff in different units. If one CNA was busy with one resident, and another resident needed help, the CNA could not leave one resident to assist another resident. In addition, CNAs in some cases cannot provide care to residents without having two people involved (ex. Using lifting machine). With the lack of communication system, it is often difficult for the CNAs to find help; they run across the unit to find an available CAN or 
LPN. This can cause a delay in assisting the residents and might lead to an adverse event. Communication going vertically in the hierarchy is also important. CNAs have reported limited communication with the nurses on the unit due to their high workload

Between two shifts, there is a 30-minute overlap. The second shift, for example, starts at 2:45 p.m., whereas the first shift ends at 3:15 p.m. During this overlap, staff members are supposed to hand off reports (CNAs to CNAs, LPNs to LPNs) and do rounding. Rounding is a means of transferring information to the staff coming on shift and giving them updates regarding the residents' current healthcare plan. Rounding usually takes place during the overlap between shifts. Staff members are supposed to check safety mechanisms during rounding and report any changes in a resident's condition-such as changes that might require immediate attention and response to call lights from these residents. However, the checklist is not always followed. Normally only two to three people go on rounds because others may be busy with tasks such as charting, and in some cases, CNAs tend to underestimate the importance of rounding and not do it. A lack of direct communication between the two shifts was observed, which might result in the lack of feedback regarding the residents' conditions.

\section{Tasks}

Residents' rooms are divided into sections and certain rooms are assigned to teams. This assignment remains unchanged for the whole month to ensure the consistency of service provided to residents. Each CNA oversees 8 to 13 residents and each LPN oversees 9 to 14 residents. There are three shifts per day with eight hours each. Day shifts have higher level of staffing than evening and night shifts.

When an alarm goes off, whether it is a call light, chair pad alarm, or a bed pad alarm, everyone should respond, including the housekeepers. There might be multiple staff members responding to an alarm until the resident is being assisted by the assigned team. Staff members communicate primarily in person. For example, two staff members may go to the same room to attend an alarm where they may also discuss another ongoing alarm and notify each other about their plans to deal with it.

The timing of the alarms also includes problems. When the alarm goes off, the patients may have already fallen $(1,18)$. Even if the staff are notified on time, they may not be able to address the resident's needs on time. For example, if they were occupied with someone else, they cannot leave that resident unless all necessary actions and procedures guaranteeing the resident's safety have been performed. This issue is more significant in the morning. Most residents wake up between 6:45 a.m. and 7:45 a.m. Numerous alarms can go off simultaneously when they all try to get out of bed or begin moving at the same time. The staff members race from one room to another. They rely on their experience and try to start with residents who cannot walk or stand by themselves. However, more than one resident need assistance from a CNA. Once, during our observation, CNAs asked the observers to watch residents several times because they could not leave another resident and no staff member was able to help. The noise from so many alarms can also confuse the staff, and noise produced from the auditory systems is almost constant. This causes discomfort for both residents and staff members. Staff can also develop alarm 
fatigue due to too many non-urgent call lights $(24,26)$. This leads to nursing staff to assume that residents do not need urgent help. This can cause them to ignore the alarms. While using a pager can reduce the noise and display the room number, nursing home staff members are constantly busy providing service for residents, which makes it difficult for them to grab the pager to see the room number.

Nursing homes are often understaffed, and nurses' stations may not always be occupied. As nursing staff are always on the move in order to care for residents, this makes using a centralized monitoring system difficult. Due to the tight schedule and understaffing, while the CNAs are working with residents, they may not be able to provide time for rounding as planned. As a result, residents with risks may not be checked as often as prescribed. Can must either stay late after the shift is over to enter updates to the electronic health record (EHR) system or to use their breaks and become exhausted after unable to take a break during their shifts.

Additionally, a single staff member may be assigned to multiple residents at the same time, this can be particularly stressful when more than one resident need attention, such as instances whereby more than one resident must be transported. While working on their own, these logistical hurdles can create chaotic moments for both the nursing home staff and their residents. Further details are included in the summary of observations in Table 1.

\section{Tools and Technologies}

Three different call light systems were observed. Included in each system were nurse station consoles which triggered an alarm to indicate a call light. All systems have lights placed above the residents' doors, and the lights come in two colors: white and either red or orange. These lights help in locating the senior using the call light. The white light indicates that the resident is asking for assistance from the bedroom, while the red or orange light indicates that the resident is asking for assistance from the bathroom.

The first call light system did not display the room number; instead, it only triggers an auditory alarm that is also broadcasted over speakers throughout the units. The auditory alarm uses a series of "beeping" at two levels of speed: slow beeping indicates that the call is coming from the bedroom, and fast beeping indicates that the call is coming from the bathroom. At the ceiling above the nurse station, there is a group of 4 lights which indicates 4 different areas in the unit. These lights turn on in response to a call light. The staff must locate the area first and then locate the resident by identifying the lights above the doors. If the lights for multiple areas are on, then the staff must check the lights above the doors in those areas.

The second call light system also used at nurses' station console. The console was could display the room number to help the CNA easily locate the room, however it could only display one room number at a time. If a new alarm was triggered, it would "cover" or override the previous room number. In this system, the only auditory warning triggered is at the nurses' stations. If the staff is working down the hallway or 
inside the residents' rooms, they could not hear the alarm. Further, there are no sound differences between a call bell in the bedroom and a call bell in the bathroom the bathroom, with the latter often reflecting more urgent needs. In one of the nursing homes, it was observed that the console was muted in one unit and was covered with a file in another unit.

The third call light observed was a pager-based system that displays the room numbers in addition to a "beeping" sound. In this system, there is also a nurse station console that can display the room number and trigger an auditory alarm. However, the system can display only one room number at a time. In case of more than one alarm, the console will keep switching between the room numbers; it will display each room number for approximately 5 seconds before switching to display the next room number. The staff must cancel the alarm from inside the resident's room and from the pager. See table 2.

Call light systems include both visual and auditory alarms. However, auditory alarms are not directional as they are broadcast through loudspeakers located at multiple spots in the hallway or only broadcasted at the nurse station area.

\section{Usability Issues of Call Light Systems}

There are many usability issues in the current employed call light systems. First, the staff is often unable to find a stopping place in there, in order to contribute to monitoring the central display of the call light. Some systems could only handle one alarm at a time. If an alarm was triggered by two or more residents, room numbers would not display until the first one was resolved, or the system would display the newest alarm and cover the previous one. In both cases, the nursing home staff have no access to feedback information about the number of alarms in the unit, if the alarms were resolved, and whether the residents were properly assisted. Not distinguishing between the alarms from bedrooms and the alarms from bathrooms (which often reflects more urgent needs) is another usability issue. In addition to reporting to the nurse station to receive notification, the staff must also look down the hall to distinguish the alarms by using the lights above the residents' room doors.

Further, the nursing home staff are working inside the resident's room most of the time. As a result, they lack access to hear the alarm when the systems trigger them from the nurse station. Additionally, systems that broadcast alarms using loudspeakers as well as other alarms in the unit constantly adjust the noise level in nursing home to a high pitch. While this is not desirable for the nursing home staff, it is even worse for the residents, the response time to call lights is long since the nurse station is not staffed most of the time. Using a pager can reduce the noise and display the room number, but the nursing home staff is always busy providing service for residents, and they cannot grab the pager to see the room number. Many staff members mute their pagers or leave them at the nurse station. Further, the auditory sound is not directional and thus is unhelpful for locating the resident's alarm. CNAs tend to locate the room by looking at lights on the top of the doors, which can also be challenging at times due to the layout. The timing of the alarms also causes problems. Usually, when the alarm goes off, the patient may 
have already fallen. For example, a resident who tries to stand up but is unable to support him- or herself may lean forward and fall.

Broken parts were also a main usability issue impeding the systems. In some units, there were many broken and non-working lights. When a resident pushed the call light button, the auditory sound would be triggered, but the light might not have worked. In some cases, because the systems were very old, the lights would turn on, but no auditory alarm would be heard. See the summary of usability issues in Table 2 .

\section{Physical Environment}

The unit layouts for the facilities observed in the present study were L- or T-shaped with one nurse station. Residents who have high risks/more critical conditions stay in the rooms closest to the nurse station.

The auditory alarms are active for most of the day. This can be obnoxious to live-in residents, as it often disrupts their rest and distracts them from their activities. The study finds that this ultimately works against the nursing homes goal of creating a comfortable environment.

The floor layout and other aspects of the physical environment are poorly designed, making it difficult for the staff to know where an alarm (e.g., a call bell) is signaling danger. The auditory alarms were broadcasted without any directional information. The door lights did not always work, and beams and doorframes blocked certain alarms from being seen, requiring staff to walk to the middle of the hallway. In most nursing homes, CNAs tend to locate the room by looking at lights on the top of the doors, so CNAs must walk to the middle of the hallway to be able to see the lights.

Having many auditory notifications in nursing homes, such as bed mats, chair mats, call light systems, and the Wander Gard system, makes nursing home environments noisy and uncomfortable for many residents to live in. During our observations, many residents complained about constantly hearing the notifications and alarms throughout the day. Consequently, the staff members sometimes had to mute the call light system in some units, which posed challenges for notifying and responding to a call light. The impact of this noisy environment is not confined to residents but also reaches and affects the staff's performance. See the summary of observation in table 1.

\section{Processes}

\section{Call Light System}

Task analysis methodology was used to analyze the task of being notified and responding to the call light system, as well as the actions the staff took to finish the task. 
The results show that the highest response time was before dinner, and this was true in both units. ANOVA analysis results showed that the unit type had no significant effect on overall response time ( $p=$ 0.856). However, timing has a significant effect on the overall response time $(p=0.014)$, while the interaction between the unit type and the time interval had no significant effect on the response time $(p=$ 0.874). In later analysis, the response time data in both units were combined due to there being no significant difference between them.

The average response time to a call light in both units was 9 minutes, these responses we're the longest before dinner time. Response to call lights in the morning were also long, around $50 \%$ of the time, CNAs responded after 5 minutes, which exceeded the administration's expectations/standards (Figure 1).

The staff did not use all the features in the system due to usability issues because the console was muted in the south unit. CNAs had to look at and track the lights all of the time. More than $16 \%$ of the time, CNAs forgot to cancel the alarm after they responded in this unit because there was no auditory alarm. This could cause a redundancy of work if another nurse noticed the light and responded to the same resident. More than $80 \%$ of the time, CNAs were notified by the light. All the cases when CNAs were notified by the display or console took place when they were near the nurse's station area where they could hear and see the display. In many cases, due to broken parts in the system, CNAs were notified by the residents (Figure 2). After pushing the button for assistance, if no one responded to them, residents tended to stand and attempt to help themselves or to go the room door to lookout and shout angrily for a nurse's attention. In more than $10 \%$ of call lights, CNAs responded and asked the resident to wait until they were done with someone else. Around $3 \%$ of the time, they forgot to come back to assist the first resident, see Figure 3.

\section{Discussion}

Approximately 34,000 fatal, life-threatening, or serious adverse events per year occur in nursing home settings, and most of these events are considered preventable $(27,28)$. A lack of effective communication policies at all levels of nursing homes were found to have contributed to these events $(27,29,30)$. Research in other healthcare settings suggests that the call light system is the link between nurses and patients during hospital stays (14). It is also recognized as a crucial piece of technology for patientcentered care models (31). It was also found to highly influence the satisfaction levels of both nursing home staff and patients $(9-11)$ and highly affect the safety of patients $(12,32)$.

In nursing homes, the call light system is the means of the initial communication between staff and residents. We endeavored to understand how nursing home staff use the system by observing their interactions and identifying the usability issues associated with the call light systems that prevent the staff from providing quality healthcare.

Nursing home staff that interact with the call light systems are often CNAs. However, according to nursing home administrations, all staff are responsible and supposed to respond to all types of alarms in the unit, such as bed/chair exist, clip alarm, weight sensors, and the call light. Device alarms are intended 
to alert and inform nursing home staff of any changes in the residents' conditions. However, the staff is subjected to too many alarms that disturb their workflow and might lead to many errors, which can contribute to mistrust and long response times $(25,26,33)$. CNAs provide most of the direct care to residents and respond to most of the alarms in the unit. However, in around $50 \%$ of the time, they responded after 5 minutes, which exceeded the administration's expectations and standards. A high alarm rate limits the CNAs ability managing the call system properly. Resulting in negative perceptions and alarm fatigue by nursing home staff. Having a high number of alarms can cause the staff to ignore the call bell occasionally. The staff was notified about call lights by residents themselves. Around $7 \%$ percent of these instances involved the residents getting out of their bed/chair and going to the room door to ask for help. The study finds that this is because the CNAs hold negative perceptions of resident's use of the call light due to frequent, non-urgent use. This ultimately causes misconceptions about the purpose of call lights due to their frequent use (34). Consequently, the staff members often muted the call light system in some units, which posed a challenge for proper notification and increased the response time to a call light. Many broken parts were observed in 3 facilities, and this may have caused malfunctions in the call light system, resulting in adverse events and contributing to a longer overall response time. These delays in responding ultimately increased the risk of residents harming themselves due to an unanswered alarm.

The physical environment of nursing homes was also found to be an issue. Nursing homes attempt to create a homelike environment; however, they are designed in hospital layouts, with L or U-shaped units, and with multiple-bedrooms located on long double-loaded hallways. The call light system has one console placed at the nurse station in the units that are unattended most of the time and lacks any directional information. In more than $70 \%$ of the observed interactions, the staff located the alarms using the lights above the doors because the consoles were not visible or accessible to them. This required that they had walked out of a resident's room or away from the nurse's station. In addition, CNAs are spending most of their time in residents' rooms providing care, and as a result, they are oblivious to the alerts of the call light, console, and auditory alarm.

The staff did not use all the features of the call light systems due to usability issues. CNAs had to look and keep track of the lights all the time. More than $16 \%$ of the time, CNAs forgot to cancel the alarm after they responded because there was no auditory alarm due to broken parts or because of continued auditory alarms in the unit. This could cause a redundancy of work if another nurse noticed the light and responded to the same resident. More than $80 \%$ of the time, CNAs were notified by the light. All the cases when CNAs were notified by the display or console took place when they were near the nurse station area where they could hear and see the display. In many cases, due to broken parts in the system, CNAs were notified by the residents. After pushing the button for assistance, if no one responds to them, they tend to stand to help themselves or go the room door to look and shout angrily asking for help.

In many cases, CNAs had to prioritize when more than one call light was triggered simultaneously or when the interval between call lights was only slightly different. Sometimes, they responded by asking the residents to wait until they were done with someone else. Around $3 \%$ of the time, they forgot to come 
back to assist the first resident. This is due to the staff's high workload and busy schedule $(15,35)$ which might also contribute to the long response time, not following the protocols such as rounding, and muting the system.

Our analysis of the call lights in nursing homes showed that most call lights were used before and after meal times. The average response time to a call light was 9 minutes, and the wait was the longest before dinnertime. This is because residents were tired at the end of the day and were ready to sleep. Response time was also long in the morning because residents tend to walk up at the same time, and everyone needs to get to the bathroom, get dressed, and have breakfast.

\section{Conclusion}

In conclusion, the call light system is critical for the interaction between the nursing home staff and residents. Research conducted in other healthcare settings has demonstrated that the call light system not only significantly improves the communication between staff and patients together (9-11), it also helps ensure the safety of patients (12). Nursing homes still using old call light systems risk the continuation of usability issues that can affect performance of the staff and contribute to a decline in staff and resident outcomes. While the healthcare industry has been at the forefront of technological advancements and implementation, it is important to recognize the importance of considering the perceptions of end users in the development of new medical technology, as well as the overall quality of healthcare service delivery $(1,2,18)$. By incorporating nurse's feedback, nursing home management will better understand the influence the perceptions and usability of technology has on the quality of healthcare for their residents.

\section{Abbreviations}

RN: Registered nurses

LPN: Licensed practical nurses

CNA: Certified nurse assistants

SEIPS model: the Systems Engineering Initiative for Patient Safety model of work system and patient safety

\section{Declarations}

Ethical approval and consent to participate:

The study was conducted after receiving an oral consent from all the staff present at the study time. The present study was approved by the Nursing Homes' ethical committees, and Binghamton University Institutional Review Board (IRB) (The protocol number is 1407000002). 
Consent for publication:

Not applicable.

Availability of data and materials:

The datasets generated and/or analyzed during the current study are not publicly available due to permission has not been applied for from neither the participants nor the nursing homes, but might be available from the corresponding author on reasonable request.

Competing interests:

The authors declare that they have no competing interests in this section.

Funding:

This study received no funding.

Author contributions:

$\mathrm{HA}$ and $\mathrm{HL}$ designed the research methodology, both conducted the first stage (participant observation). HA collected and analyzed the data for the second stage and drafted the manuscript. Both authors made critical revision of the manuscript and approved the final version.

Acknowledgements:

Not applicable

\section{References}

1. Krauss MJ, Evanoff B, Hitcho E, Ngugi KE, Dunagan WC, Fischer I, et al. A case-control study of patient, medication, and care-related risk factors for inpatient falls. Journal of general internal medicine. 2005;20(2):116-22.

2. Roszell $S$, Jones $C B$, Lynn MR. Call bell requests, call bell response time, and patient satisfaction. Journal of nursing care quality. 2009;24(1):69-75.

3. Ali $\mathrm{H}, \mathrm{Li} \mathrm{H}$. Evaluating a smartwatch notification system in a simulated nursing home. International Journal of Older People Nursing. 2019;0(0):e12241.

4. Ali H, Li H, Wong J. Evaluating a Smartwatch-based Notification System in a Simulated Nursing Home: The Method. Proceedings of the International Symposium on Human Factors and Ergonomics in Health Care. 2017;6(1):132-8.

5. Castle NG, Ferguson JC. What is nursing home quality and how is it measured? Gerontologist. 2010;50(4):426-42. 
6. Lee HY, Blegen MA, Harrington $\mathrm{C}$. The effects of RN staffing hours on nursing home quality: a twostage model. Int J Nurs Stud. 2014;51(3):409-17.

7. Li H, Ali H. Human Factors Considerations in the Design of Falls Prevention Technologies for Nursing Homes: A Case Study. Proceedings of the International Symposium on Human Factors and Ergonomics in Health Care. 2015;4(1):97-102.

8. Galinato J, Montie M, Patak L, Titler M. Perspectives of Nurses and Patients on Call Light Technology. Computers, informatics, nursing: CIN. 2015;33(8):359-67.

9. Cardoso G, Martin N. The Patient Connection: Improving Call Bell Response at Cambridge Memorial Hospital. Healthcare Management Forum. 2003;16(3):47-50.

10. Stokowski LA. Ring for the nurse! Improving call light management. 2008.

11. Deitrick L, Bokovoy J, Stern G, Panik A. Dance of the call bells: using ethnography to evaluate patient satisfaction with quality of care. Journal of nursing care quality. 2006;21(4):316-24.

12. Meade CM, Bursell AL, Ketelsen L. Effects of Nursing Rounds: on Patients' Call Light Use, Satisfaction, and Safety. AJN The American Journal of Nursing. 2006;106(9):58-70.

13. Tzeng HM, Yin CY. The extrinsic risk factors for inpatient falls in hospital patient rooms. Journal of nursing care quality. 2008;23(3):233-41.

14. Tzeng HM, Yin CY. Predicting Patient Satisfaction With Nurses' Call Light Responsiveness in 4 US Hospitals. JONA: The Journal of Nursing Administration. 2010;40(10):440-7.

15. Chung G. Understanding Nursing Home Worker Conceptualizations about Good Care. Gerontologist. 2012;53(2):246-54.

16. Schoville RR. Guiding Healthcare Technology Implementation: A New Integrated Technology Implementation Model. 2015;33(3):99-107.

17. Lehoux P, Daudelin G, Williams-Jones B, Denis JL, Longo C. How do business model and health technology design influence each other? Insights from a longitudinal case study of three academic spin-offs. Research Policy. 2014;43(6):1025-38.

18. Ali H, Li H, editors. Designing a Smart Watch Interface for a Notification and Communication System for Nursing Homes. Human Aspects of IT for the Aged Population Design for Aging; 2016; Cham: Springer International Publishing.

19. Barnard A. Technology and nursing: an anatomy of definition. International Journal of Nursing Studies. 1996;33(4):433-41.

20. While A, Dewsbury G. Nursing and information and communication technology (ICT): a discussion of trends and future directions. Int J Nurs Stud. 2011;48(10):1302-10.

21. Norman DA. User Centered System Design: New Perspectives on Human-computer Interaction. 1986.

22. Carayon P, Schoofs Hundt A, Karsh BT, Gurses AP, Alvarado CJ, Smith M, et al. Work system design for patient safety: the SEIPS model. Qual Saf Health Care. 2006;15 Suppl 1(Suppl 1):i50-i8.

23. Edwards $C$. Using interdisciplinary shared governance and patient rounds to increase patient safety. Medsurg nursing: official journal of the Academy of Medical-Surgical Nurses. 2008;17(4):255-7. 
24. Creighton Graham K, Maria C. Monitor Alarm Fatigue: Standardizing Use of Physiological Monitors and Decreasing Nuisance Alarms. American journal of critical care: an official publication, American Association of Critical-Care Nurses. 2010(19):28-34.

25. Siebig S, Kuhls S, Imhoff M, Gather U, Scholmerich J, Wrede CE. Intensive care unit alarms-how many do we need? Critical care medicine. 2010;38(2):451-6.

26. Graham KC, Cvach M. Monitor alarm fatigue: standardizing use of physiological monitors and decreasing nuisance alarms. American journal of critical care: an official publication, American Association of Critical-Care Nurses. 2010;19(1):28-34; quiz 5.

27. Field TS, Tjia J, Mazor KM, Donovan JL, Kanaan AO, Harrold LR, et al. Randomized trial of a warfarin communication protocol for nursing homes: an SBAR-based approach. The American journal of medicine. 2011;124(2):179.e1-7.

28. Gurwitz JH, Field TS, Judge J, Rochon P, Harrold LR, Cadoret C, et al. The incidence of adverse drug events in two large academic long-term care facilities. The American journal of medicine. 2005;118(3):251-8.

29. Husebo BS, Flo E, Aarsland D, Selbaek G, Testad I, Gulla C, et al. COSMOS-improving the quality of life in nursing home patients: protocol for an effectiveness-implementation cluster randomized clinical hybrid trial. Implementation science: IS. 2015;10:131.

30. Kane RA. Definition, Measurement, and Correlates of Quality of Life in Nursing Homes: Toward a Reasonable Practice, Research, and Policy Agenda. Gerontologist. 2003;43(suppl_2):28-36.

31. Duffy JR, Kooken WC, Wolverton CL, Weaver MT. Evaluating patient-centered care: feasibility of electronic data collection in hospitalized older adults. Journal of nursing care quality. 2012;27(4):307-15.

32. Tzeng HM. Using multiple data sources to answer patient safety-related research questions in hospital inpatient settings: a discursive paper using inpatient falls as an example. Journal of Clinical Nursing. 2011;20(23-24):3276-84.

33. Schmid F, Goepfert MS, Kuhnt D, Eichhorn V, Diedrichs S, Reichenspurner H, et al. The wolf is crying in the operating room: patient monitor and anesthesia workstation alarming patterns during cardiac surgery. Anesthesia and analgesia. 2011;112(1):78-83.

34. Tzeng HM. Perspectives of staff nurses of the reasons for and the nature of patient-initiated call lights: an exploratory survey study in four USA hospitals. BMC Health Services Research. 2010;10(1):52.

35. Chui MA, Mott DA, Maxwell L. A qualitative assessment of a community pharmacy cognitive pharmaceutical services program, using a work system approach. Res Social Adm Pharm. 2012;8(3):206-16.

\section{Tables}

Table 1: Summary of Observations 
Components of the SEIPS model

Person

Organization

Task

Environment

Technology/tools

Process
Summary of observations

-Most of the staff are females

-Staff: Registered nurses (RNs): designating the nursing assignments, making up the working schedules, residents treatment plans, administering medicine (IV, blood, etc.), in addition to their supervisory role (primary care managers)

Licensed practical nurses (LPNs): direct bedside care, vital signs, administer medication, collecting samples for testing, feeding patients who use feeding tubes, and perform other procedures.

Certified nurse assistants (CNAs): routine tasks in the provision of personal care to residents such as eating, dressing, bathing, getting in and out of bed, Staff shortage

-Unit: long-term care and short-term care unit

Three shifts

-Other: Lack of teamwork, poor working conditions, -Incompliance with protocols:

overrule rounds, mute the system,

LPNs tend to not respond (all the staff have to respond to alarms), long response time (expectation is 5 minutes to respond to a call light), lack of collaboration (teamwork, difficulties in finding help) and communication, Nurse station is not staffed

-Poor maintenance of the system: many broken parts

-Control over the practice and supervisor support:

Schedule is flexible to some degree,

Limitation in providing input/suggestions, staff shortage, blame staff in case of adverse events such as falls

-Responding to a call light:

All staff are expected to respond within 5 minutes

-High mental and physical workload: Information processing \& memory (divided and multitasking: slower and less accurate tasks, change blindness), interruptions, "diagnosticity" (staff perceptions about call lights), alarm fatigue

\section{-Layout:}

Not visible (display at nurse station), lights above the resident's rooms are not visible (blocked by beams and doors), long hallways (hard to hear)

-Noise:

Loudspeakers to broadcast alarms, alarm is on most of the time, residents complaining about the noise

\section{-Usability issues:}

Nurse station is not occupied, no directional information, lack of prioritization and low/no discriminability (e.g. is it bathroom or bedroom?), broken parts, location position of display, system can be muted by the staff, handle only one alarm at a time, new alarm "overwrites" previous alarm, no feedback about the previous alarm, false alarms, loud speakers, lights to indicate different area (lack of natural mapping), lack of auditory change detection (sounds are not memorized), not effective

To be notified about a call light and locate the call light 
Table 2: Call light system observed, and the usability issues associated with each system. 


\begin{tabular}{|c|c|c|}
\hline $\begin{array}{l}\text { Call light } \\
\text { system type }\end{array}$ & System description & $\begin{array}{l}\text { Usability issues and challenges } \\
\text { with the system }\end{array}$ \\
\hline $\begin{array}{l}\text { Traditional/ } \\
\text { type } 1\end{array}$ & $\begin{array}{l}\text {-Two lights above residents' room } \\
\text {-One console without a display at } \\
\text { nurse station } \\
\text {-4 lights at the ceiling above the } \\
\text { nurse station area to indicate } 4 \\
\text { different areas in the unit } \\
\text {-Auditory alarms are broadcasting } \\
\text { at nurse station in addition to } \\
\text { multiple locations in the unit } \\
\text {-2 speeds of auditory alarms, slow } \\
\text { beeping for bedrooms call, and } \\
\text { fast beeping for bathroom calls } \\
\text {-One nurse station in a U-shaped } \\
\text { unit } \\
\text {-Alarms can be canceled from } \\
\text { residents' rooms }\end{array}$ & $\begin{array}{l}\text {-Nurse station is not occupied; no } \\
\text { one to monitor the console/central } \\
\text { display } \\
\text { - Low/no discriminability; } \\
\text { - Lack of prioritization } \\
\text { If more than one area light is on, } \\
\text { staff must check all these areas } \\
\text {-Noise; Load speakers } \\
\text { - False alarms due to broken parts } \\
\text { - Lack of Feedback } \\
\text {-Noise } \\
\text { - Lights above the resident's } \\
\text { rooms are not visible due to } \\
\text { layout }\end{array}$ \\
\hline $\begin{array}{l}\text { Traditional/type } \\
2\end{array}$ & $\begin{array}{l}\text {-Two lights above residents' doors } \\
\text {-Console with display at nurse } \\
\text { station } \\
\text {-Auditory alarms are broadcast at } \\
\text { nurse station } \\
\text {-One nurse station in a T-shaped } \\
\text { unit } \\
\text {-Alarms can't be heard from inside } \\
\text { rooms at the end of the hallways } \\
\text {-No sound differences between } \\
\text { alarms from bedroom and } \\
\text { bathroom } \\
\text {-Staff can mute the console } \\
\text {-Alarms can be canceled from } \\
\text { residents' rooms }\end{array}$ & $\begin{array}{l}\text {-The nurse station is not staffed. } \\
\text {-Console can only display one } \\
\text { room number } \\
\text { - Low/no discriminability; is } \\
\text { bedroom or bathroom } \\
\text { - Lack of prioritization } \\
\text { - Many broken parts / false } \\
\text { alarms, redundancy of work } \\
\text { - Console and auditory alarms are } \\
\text { not accessible from residents' } \\
\text { room and end of the hallways } \\
\text { - The new alarm "overwrites" } \\
\text { previous alarm. } \\
\text {-The lights above the resident's } \\
\text { rooms are not visible due to } \\
\text { layout. } \\
\text {-The system can be muted by the } \\
\text { staff }\end{array}$ \\
\hline $\begin{array}{l}\text { Pager-based } \\
\text { system }\end{array}$ & $\begin{array}{l}\text {-Console with a display at the } \\
\text { nurse station } \\
\text {-The console can only display one } \\
\text { room number and will keep } \\
\text { switching between different room } \\
\text { numbers in case of more than one } \\
\text { alarm } \\
\text {-Auditory alarms are broadest on } \\
\text { the nurse station in addition to a } \\
\text { beeping sound from the pagers }\end{array}$ & $\begin{array}{l}\text { - The nurse station is not staffed. } \\
\text {-There is a lack of directional } \\
\text { information. } \\
\text {-Console switch between room } \\
\text { number every } 5 \text { seconds it will, } \\
\text { staff might cancel the wrong } \\
\text { alarm } \\
\text {-Pagers are muted most of the } \\
\text { time }\end{array}$ \\
\hline
\end{tabular}

Page 19/21 
-Alarms must be canceled from both, residents' rooms and the pagers
-Staff has busy schedule, can't grab the pager every time they have an alarm.

-CNAs must make trips to the nurse station to cancel the alarm, alarms must be canceled from both pager and console/ center display.

-The lights above the resident's rooms are not visible due to layout.

-Staff might take a pager that is not for them (they take the pager at the beginning of the shift).

\section{Figures}

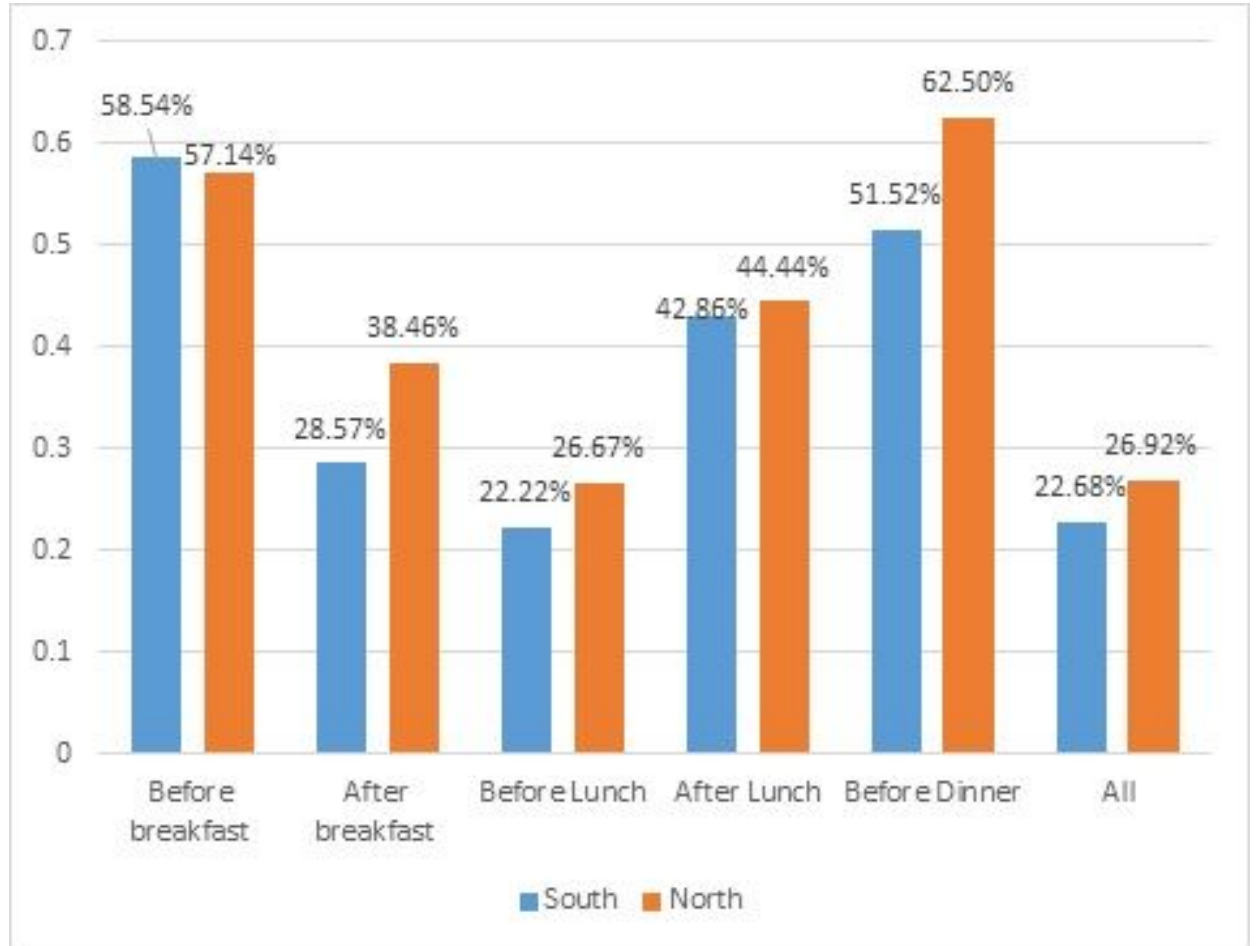

Figure 1

Figure 1: Percentage of call lights that do not meet the 5-minute standard in both units during different time intervals. 


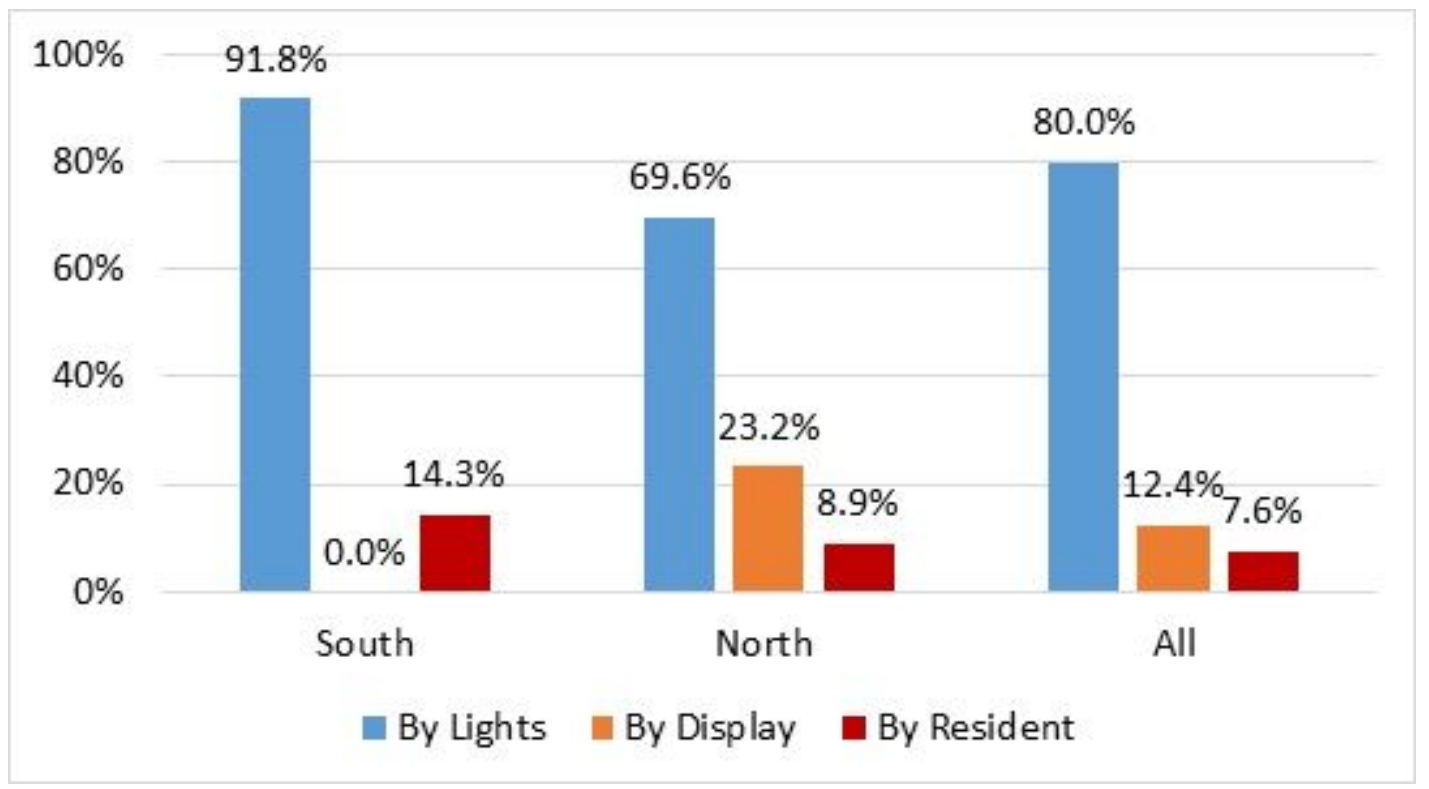

Figure 2

Figure 2: Notification process

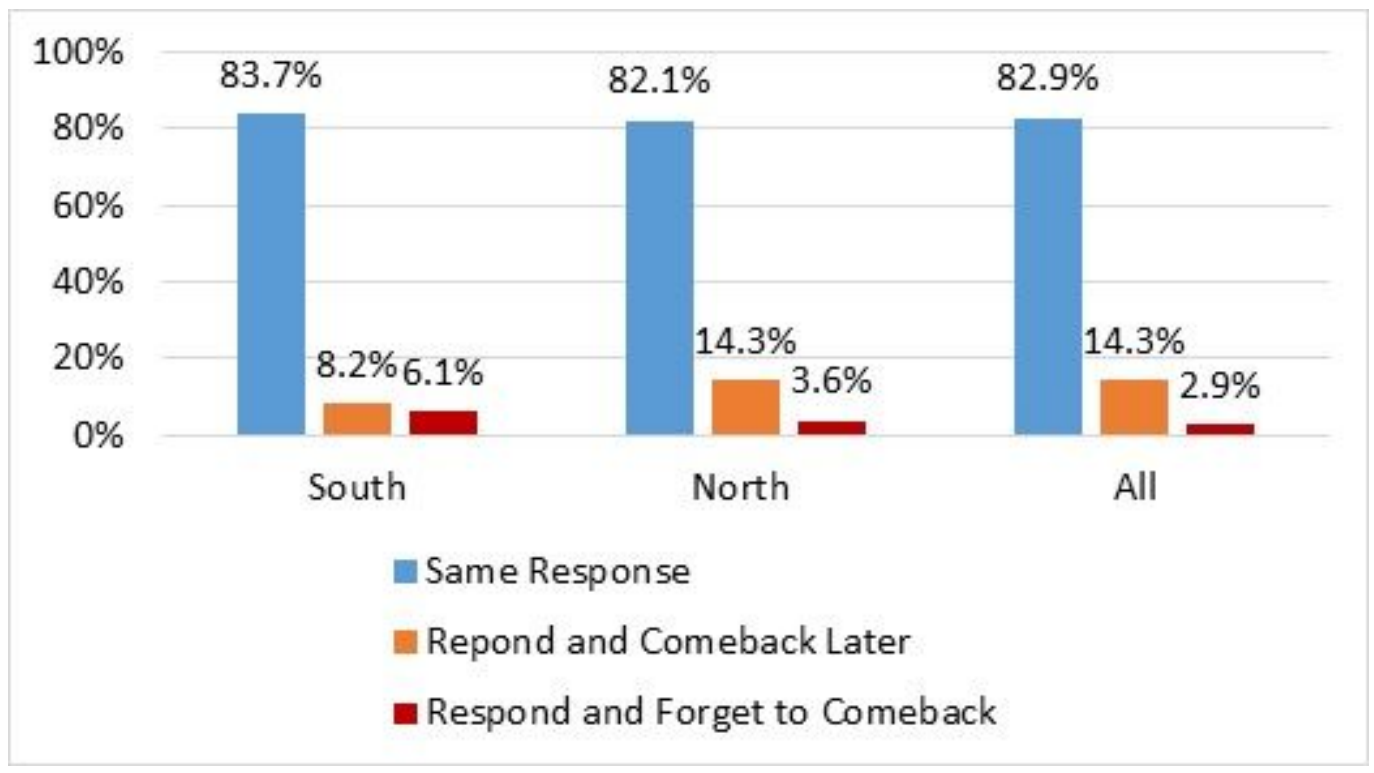

Figure 3

Figure 3: Responding process

\section{Supplementary Files}

This is a list of supplementary files associated with this preprint. Click to download.

- supplement1.docx 